\title{
Probabilistic forecasting of wind power production losses in cold climates: a case study
}

\author{
Jennie Molinder ${ }^{1}$, Heiner Körnich ${ }^{2}$, Esbjörn Olsson ${ }^{2}$, Hans Bergström ${ }^{1}$, and Anna Sjöblom ${ }^{1}$ \\ ${ }^{1}$ Department of Earth Sciences, Uppsala Universite, Uppsala, Sweden \\ ${ }^{2}$ Swedish Meteorological and Hydrological Institute, Norrköping, Sweden
}

Correspondence: Jennie Molinder (jennie.molinder@geo.uu.se)

Received: 3 July 2017 - Discussion started: 18 September 2017

Revised: 29 June 2018 - Accepted: 12 September 2018 - Published: 9 October 2018

\begin{abstract}
The problem of icing on wind turbines in cold climates is addressed using probabilistic forecasting to improve next-day forecasts of icing and related production losses. A case study of probabilistic forecasts was generated for a 2-week period. Uncertainties in initial and boundary conditions are represented with an ensemble forecasting system, while uncertainties in the spatial representation are included with a neighbourhood method. Using probabilistic forecasting instead of one single forecast was shown to improve the forecast skill of the ice-related production loss forecasts and hence the icing forecasts. The spread of the multiple forecasts can be used as an estimate of the forecast uncertainty and of the likelihood for icing and severe production losses. Best results, both in terms of forecast skill and forecasted uncertainty, were achieved using both the ensemble forecast and the neighbourhood method combined. This demonstrates that the application of probabilistic forecasting for wind power in cold climates can be valuable when planning next-day energy production, in the usage of de-icing systems and for site safety.
\end{abstract}

\section{Introduction}

Wind power production in cold climates experiences significant problems with production losses because of icing. Icing on the turbine blades reduces the energy production due to a change in the aerodynamic balance, generation of vibration and increased load (Kraj and Bibeau, 2010). Furthermore, site safety is an issue since falling ice poses a threat to the public and to maintenance. Despite these complications, a substantial part of the wind power production is located in cold climate regions. This geographical choice results from both the possible higher production in lower temperatures where the air is more dense than in warmer regions, and from the low population density, which reduces public safety risks and disturbance. According to the World Market Update 2012 (Wallenius et al., 2013), more than $24 \%$ of the global wind energy capacity was located in cold climate regions at the end of 2012 and most of these turbines experience between light and heavy icing. In order to plan for next-day energy production and site safety, short-range fore- casts of icing and related production losses are vital tools for the energy market.

Forecasting icing and related production losses is challenging due to uncertainties in both the meteorological conditions and the modelling of the involved processes (e.g. Bergström et al., 2013; Davis et al., 2014). A common approach for the modelling chain is shown in Fig. 1. A numerical weather prediction (NWP) model is used to forecast meteorological parameters that serve as input to an icing model. Finally, a statistical production model calculates the icingrelated production losses from the forecasted wind and icing. It should be noted that all steps in the modelling chain of Fig. 1 contain uncertainties, either in the model formulation or the required input data. The NWP model and the icing model suffer from a lack of knowledge about the physical processes, from the numerical discretization and from simplifications to make the models computationally affordable for operational use (Yano et al., 2015). Initial conditions for the NWP model are also uncertain due to errors in the meteorological observations and assumptions in data assimilation 


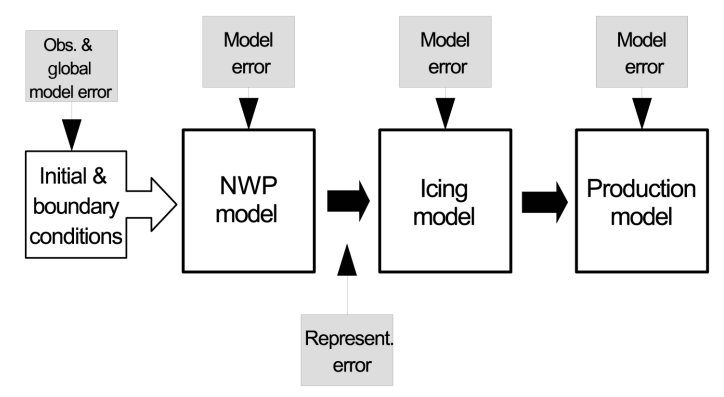

Figure 1. The modelling chain for forecasting icing-related production losses. Uncertain parts are pointed out.

methods (Megner et al., 2015). Forecasting wind power production requires high horizontal resolution of the order of kilometres to capture wind fields at $100 \mathrm{~m}$ above ground in the Scandinavian mountains and also to model small-scale atmospheric phenomena leading to icing (Bergström et al., 2013). Due to the computational needs of such models, the domain size is limited and lateral boundary conditions are provided by a host model, adding further uncertainties in the modelling chain. Finally, a statistical production model is based on a limited set of previous forecast validations and on assumptions about the functional relationship between wind, ice and production, also resulting in uncertainties. Because of these error sources in the modelling chain, the forecasted production losses are uncertain. This issue has been addressed by using different NWP models that result in different estimations of ice load and icing intensity, and hence production losses (Ronsten et al., 2012; Bergström et al., 2013). Here, we address this problem in another way.

A common approach for uncertainty quantification in NWP is to use ensemble forecasting (Leith, 1974). It is known that in a non-linear dynamical system such as the weather, the largest uncertainty results from initial errors growing rapidly with forecast time. These errors can be represented by re-running the model multiple times, starting from slightly different initial conditions (Leutbecher and Palmer, 2008). This collection of forecasts is generated by an ensemble prediction system (EPS). Global EPSs have been run since the early 1990s at, for example, the European Centre of Medium-range Weather Forecasts (ECMWF). In the beginning, the focus of ensemble forecasting lay mostly on medium-range global forecasting. In the last $10-15$ years, meso-scale EPS has been developed at different weather centres (e.g. the Met Office, Bowler et al., 2008, and NOAA, Du et al., 2003) addressing the uncertainties in the short range, i.e. during the first $48 \mathrm{~h}$ of the forecast.

An ensemble forecast can be used in several ways. The ensemble mean generally has a lower error than a single forecast, because the less predictable parts have been filtered out when averaging the ensemble members (WMO, 2012). This method was used by Al-Yahyai et al. (2011) to estimate the average wind speed over Oman in different seasons, and the ensemble mean reduced the forecast error compared to a single forecast. The difference between, or the spread of, the ensemble members can represent the uncertainty of the forecast. An ensemble forecast can also be used probabilistically to estimate the likelihood of a specific event; for example, the timing of a sudden change in wind speed (Schäfer, 2014). Furthermore, an EPS for short-range forecasting has been investigated for wind energy purposes (e.g. Pinson and Kariniotakis, 2010; Traiteur et al., 2013). Traiteur et al. (2013) studied the use of a short-range EPS for $1 \mathrm{~h}$ wind speed forecasting and showed that a statistically calibrated EPS outperforms other forecast methods. Here, we will employ an EPS for forecasting icing-related wind power losses.

An additional uncertainty arises due to the fact that kilometre-scale phenomena, such as convective clouds, have faster forecast error growth than phenomena on larger scales, such as the position of a low-pressure system. Thus, a forecasted small-scale cloud can be misplaced by some tens of kilometres generating an error in spatial representation. This uncertainty has implications for how the forecast can be interpreted at a specific wind turbine location. Mittermaier (2014) suggested the use of the neighbourhood method in order to address this misplacement of small-scale features in forecasts. In this method, a selected number of the surrounding grid points to an observation site are treated as equally likely forecasts. These forecasts can then be used in the same way as an ensemble, accounting for the uncertainties in the representativeness at each wind turbine location. An approach to generate probabilistic forecasts of wind power, called adapted resampling, was already used earlier by Pinson and Kariniotakis (2010), where the value of probabilistic forecasting for trading and wind power management was demonstrated and it was suggested that methods of wind power forecasting should not rely directly on point forecasts as input.

In this case study, probabilistic next-day forecasts for wind power in cold climates has been run for a 2 -week period in winter 2011/2012. The modelling chain (Fig. 1) is extended with meso-scale ensemble forecasts and the neighbourhood method. These extensions address the uncertainties in the initial and boundary conditions as well as the representation error of the NWP part. In order to examine the impact of these terms separately, different combinations of ensemble forecasting and the neighbourhood method are examined as the uncertainty quantification of the forecast for icing and related production losses. Thus, it will be investigated whether these probabilistic methods add value to specific challenges of wind power forecasting in cold climates.

The models in the modelling chain are described in Sect. 2.1. The specific experiment period and available observational data are described in Sect. 2.2. The different approaches for the uncertainty quantification are presented in Sect. 2.3 and the verification methods in Sect. 2.4. The results in Sect. 3 are divided into two parts: meteorological pa- 
rameters in Sect. 3.1 and forecasts of icing and production losses in Sect. 3.2. Concluding remarks are given in Sect. 4.

\section{Method}

\subsection{Description of the models}

\subsubsection{NWP model}

As the NWP model, the ensemble prediction system HarmonEPS is used. HarmonEPS is a non-hydrostatic, convection-permitting model intended for predictions of probabilities of high-impact weather events. It is based on the ALADIN-HIRLAM shared system and contains two packages of physical parameterizations, AROME and ALARO, of which the AROME package (cy38h1.2) was used here in the HARMONIE-AROME configuration (Bengtsson et al., 2017). HARMONIE-AROME has been used for operational weather forecasts at the Swedish Meteorological and Hydrological Institute (SMHI) since 2014 (Müller et al., 2017), also as an ensemble in HarmonEPS since 2016. In the present study, the horizontal resolution of the model is $2.5 \mathrm{~km}$ and it has 65 vertical levels. The model domain can be seen in Fig. 2. The lateral boundary conditions come from the global EPS at the ECMWF with an horizontal resolution of $30 \mathrm{~km}$ and are updated at 00:00 and 12:00 UTC. A spin-up period of 3 weeks was used to generate the start of the forecast period. The HarmonEPS ensemble consists of 10 perturbed members and 1 control member. The number of ensemble members was chosen based on a short-range EPS study, by Du et al. (1997), where it was shown that 8-10 ensemble members are sufficient for at least $90 \%$ of the possible benefit of using an EPS. Since an EPS is computationally demanding to run, 10 members were therefore considered to be sufficient for the present study. The control member is using 3-D-variational data assimilation of conventional observations as well as satellite observations from the instruments AMSU-A and AMSU-B, with $6 \mathrm{~h}$ cycling. For the generation of the initial conditions for the ensemble members, the so-called PERTANA option is used, where the difference between the control analyses of HarmonEPS and ECMWF is added to the fields from the ECMWF EPS-perturbed members. The HarmonEPS set-up used here differs from the operational HarmonEPS currently running at SMHI in several aspects: the operational version uses a new model version (cy40h1.1), boundary conditions with the scaled lagged average forecast method and also some physics perturbations (Andrae and MetCoOp-Team, 2017). As the control member has no perturbations on the initial and boundary conditions, it should statistically outperform the other ensemble members.

\subsubsection{Postprocessing of the NWP data}

Despite of increasingly higher resolution, the NWP models still lack some topographic details. The height of mountaintops in the model terrain remains, in most cases, below the

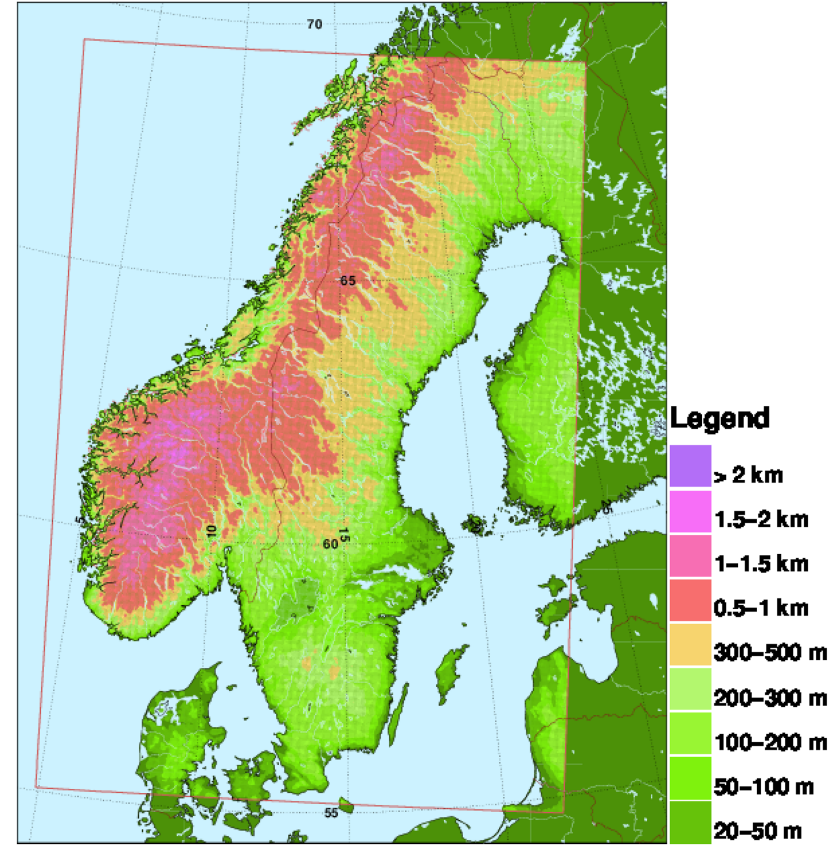

Figure 2. NWP model domain. Colours represent topography described in legend.

actual height. The NWP output parameters are therefore adjusted to account for the difference between model terrain and real topography. The following vertical interpolation is used for the NWP output; here for the example of temperature $(T)$ :

$T_{\mathrm{i}}=\frac{T\left(h_{\mathrm{m}}+\Delta h+h_{\text {nacelle }}\right)+T\left(h_{\mathrm{m}}+h_{\text {nacelle }}\right)}{2}$,

where $T_{\mathrm{i}}$ is the vertically interpolated temperature, $h_{\mathrm{m}}$ is the model terrain height, $\Delta h$ is the difference between the real terrain height and the model terrain height, and $h_{\text {nacelle }}$ is the height of turbine nacelle. Effectively, the forecast made at the actual terrain height plus nacelle height and the forecast made at the model terrain height plus nacelle height are averaged in Eq. (1). This averaging method was employed since using only the forecast data at the actual height over sea level for the wind turbine nacelle can result in using atmospheric parameters well above the terrain compared to the turbine height. On the other hand, using only the forecast data at the height of the turbine nacelle above the model terrain can result in atmospheric data at lower height than the actual height of the wind turbine. This interpolation is done for all atmospheric parameters that serve as input to the icing model. It should be noted that in the case where model terrain height is higher than the real terrain height, only the model terrain height is used. However, no such grid point was found in the current study. 


\subsubsection{Icing model}

The meteorological parameters forecasted by the NWP model are used to calculate ice loads utilizing a cylindrical ice accretion model. The model is following the ISO standard with a cylinder of $30 \mathrm{~mm}$ in diameter and is based on an equation often referred to as the Makkonen equation:

$$
\frac{\mathrm{d} M}{\mathrm{~d} t}=\sum_{i=1}^{5} \alpha_{1} \alpha_{2} \alpha_{3} W v A-L,
$$

where $M$ is the mass of ice; $t$ is the time, the sum represent the sum of the ice accumulation due to the different hydrometeors such as rain, cloud water, snow, graupel and cloud ice; $\alpha_{1}, \alpha_{2}$ and $\alpha_{3}$ are efficiency coefficients; $W$ is liquid water content; $v$ is wind speed; $A$ is the cross-sectional area of the cylinder on which the ice accumulation is calculated (Makkonen, 2000) and $L$ is the ice loss term which is an addition to the original Makkonen model. $L$ includes functions for melting, sublimation, wind erosion and ice shedding. The efficiency coefficients take into account aspects of the object where the ice is accumulated, such as the possibility for water adhering to the surface. A detailed description of the coefficients is found in Makkonen (2000). Meteorological inputs needed for the ice calculations are temperature, wind speed, liquid/solid water content, relative humidity and median volume droplet size. The latter is not directly available from the present NWP models, so a value is estimated for all water components based on the liquid/solid water content and the concentration of droplets. The concentration of cloud droplets is set to a constant of $100 \mathrm{~cm}^{-1}$ except in the case of precipitation, when the number of droplets is instead based on output from the NWP model.

In addition to the original Makkonen equation, which only accounts for ice accretion due to cloud water, ice accretion due to cloud ice, graupel, snow and rainwater are included in the icing model. It is assumed that snow and graupel are only contributing to the ice accretion if rain or cloud water is also present since dry snow easily re-bounces after the collision with the turbine. The sticking efficiency $\alpha_{2}$ is different for snow and graupel compared to cloud water. Based on Nygaard et al. (2013) where both $\alpha_{2}=1 / v^{0.5}$ and $\alpha_{2}=1 / v$ were discussed, $\alpha_{2}=1 / v^{0.75}$ is used here. For simplicity, the accretion efficiency $\alpha_{3}$ is calculated in the same manner for the liquid and solid water components. The different forms of water in the cloud are fed separately into the equations using their forecasted concentrations from the NWP model. The equations for calculating droplet number concentrations for cloud ice, rain, snow and graupel have been taken from the AROME microphysics scheme (Seity et al., 2011). The median volume droplet diameter is calculated according to a scheme for cloud water by Thompson et al. (2008).

Formulas for melting, shedding, sublimation and wind erosion are also additions to the model compared to the original Makkonen equation. Melting of ice is calculated using an energy balance equation, which includes an empirical ice shedding. The ice shedding is simulated by multiplying a constant of 8 with the melting term, increasing the process of removing the ice by a factor of 8 . The sublimation is calculated using Eq. (19) in Mazin et al. (2001), which uses wind speed and relative humidity in the calculations. The wind erosion is calculated by multiplying an hourly rate coefficient of $10 \mathrm{~g} \mathrm{~m}^{-2}\left(\mathrm{~m} \mathrm{~s}^{-1}\right)^{-1}$ with the wind speed when the wind speed is greater than $5 \mathrm{~m} \mathrm{~s}^{-1}$, otherwise the erosion is zero. Here, only the wind speed at the nacelle is used. If the actual winds at the rotating wind turbine are used, the wind erosion coefficient needs to be reduced approximately by a factor of 10 (Davis et al., 2016).

A more detailed documentation of the icing model can be found in Bergström et al. (2013). It should be noted that there are some differences in the model version since used in Bergström et al. (2013) as described above, i.e. the additional wind erosion calculations and the height interpolation.

\subsubsection{Production model}

The production model consists of two parts, one part for the potential production and one for the production loss.

Ice-free seasonally varying power curves were calculated for each wind turbine at every wind park, using a minimum of 2 years of production and wind speed observations. Only production observations with temperatures above $5^{\circ} \mathrm{C}$ were used to ensure that the blades are free of ice. The power curves are then used with forecasted wind speed to calculate the potential production.

The production loss forecast requires the modelled parameters of ice intensity, ice load and wind speed as input. It uses two matrices separating the losses due to ice load and icing intensity (Bergström et al., 2013). For a specific wind speed, ice load and icing intensity, the model yields a production loss in percent. Only one of the matrices is used for each forecast depending on which gives the highest production loss. The matrices were constructed manually using hindcasts of ice load and wind speed from a 2-month period in 2010 combined with observed production values from one specific wind park, which showed good agreement between observed and modelled icing. Due to contractual reasons, the wind park will not be specified. The matrices were generated by fitting $0 \%$ and $100 \%$ losses against observations and then by linearly interpolating the values in between. The empirical functions for production loss, determined for one specific wind farm, were used in the production forecasts for all wind farms. Generally, the icing intensity influences the production losses more than the ice load (Bergström et al., 2013). Finally, the potential production is combined with the forecasted loss to provide the actual forecasted production output. 
Table 1. Observation sites with approximate latitude, description if the measurements were made from a mast or at the wind turbine nacelle (WT) and available production data $(x)$.

\begin{tabular}{lllllllllll}
\hline Site & $\mathrm{A}$ & $\mathrm{B}$ & $\mathrm{C}$ & $\mathrm{D}$ & $\mathrm{E}$ & $\mathrm{F}$ & $\mathrm{G}$ & $\mathrm{H}$ & $\mathrm{I}$ & $\mathrm{J}$ \\
\hline Latitude & $65^{\circ} \mathrm{N}$ & $67^{\circ} \mathrm{N}$ & $58^{\circ} \mathrm{N}$ & $68^{\circ} \mathrm{N}$ & $68^{\circ} \mathrm{N}$ & $68^{\circ} \mathrm{N}$ & $62^{\circ} \mathrm{N}$ & $60^{\circ} \mathrm{N}$ & $60^{\circ} \mathrm{N}$ & $58^{\circ} \mathrm{N}$ \\
WT or Mast & WT & WT & WT & Mast & Mast & Mast & Mast & WT & WT & Mast \\
Production data & $\times$ & $\times$ & $\times$ & & & & & & & \\
\hline
\end{tabular}

\subsection{Experiment period and available data}

The case study is based on a 2-week period. HarmonEPS was run from 26 December 2011 to 7 January 2012, initializing a $42 \mathrm{~h}$ long forecast at 00:00, 06:00, 12:00 and 18:00 UTC, with hourly output. The forecasted values from 18 to $42 \mathrm{~h}$ starting from 06:00 UTC are used as the "next-day" forecast in the evaluation of the forecasted production losses and production.

Observations are available from 10 wind parks in Sweden that will not be specified due to contractual reasons. At some sites the observations were made from meteorological masts and at others at the turbine nacelle. All 10 sites measure temperature, wind speed, wind direction, relative humidity, pressure and ice load. The sites are located from northern to southern Sweden between 250 and $1000 \mathrm{~m}$ above sea level and the measurement height above ground is between 60 and $150 \mathrm{~m}$. From three of the sites, production data from each turbine is available for the period. The approximate location of the sites can be seen in Table 1 together with a specification if mast or nacelle (WT) observations were available and if the site had production data. The three sites with production data are at some distance from each other (Table 1). Site A is located on a hill with relatively high terrain west and north of the site, and somewhat lower terrain toward the south and east. In the location of site B, there is a similar terrain height to the south and west, while the terrain to the north and east is lower. The hill of site $\mathrm{C}$ extends mainly in the south-north direction, with lower terrain to the west and east. Site B and $\mathrm{C}$ have around 10 wind turbines, while site A consists of 20 turbines. All sites are surrounded with forest and with some lakes at lower levels. For each site, one single value of production data is calculated by averaging production data from wind turbines without an error code. No de-icing system was used on the wind turbines included in the study.

The meteorological parameters are measured every $10 \mathrm{~min}$ with the instrument Quatro-Ind H (Lambrecht Meteorological Instruments, Germany), except at one site where the instrument WXT510 (Vaisala, Finland) is used. Since the NWP forecast output is hourly, only the $10 \mathrm{~min}$ observations at every full hour are used in the verification.

The ice load is measured with an IceMonitor (Combitech $\mathrm{AB}, 2016)$. The IceMonitor measures ice on a rotating cylinder according to ISO 123494 specifications (ISO 12494, 2001). Some problems have been identified with this instrument. One is that it may stop rotating, and the ice is then only accumulated on one side of the cylinder. Another issue is that the ice can cause the rod to lift and thus to measure an incorrect ice load (Thorsson et al., 2015). Therefore, it is difficult to use the ice measurements quantitatively, but they are still used here to get an approximate observation of the icing.

The following quality controls were conducted for the observations of temperature $(T)$, wind speed (WS) and relative humidity (RH). Values for $T<-40^{\circ} \mathrm{C}$, WS $<0 \mathrm{~m} \mathrm{~s}^{-1}$ and $\mathrm{RH}<0 \%$ are removed from the data set as being unrealistic. Also, if the standard deviation of the $10 \mathrm{~min}$ averaged wind speed was zero, the observation was removed. Finally, in order to remove unrealistic jumps in the observations, the following check was performed: if the difference between the current observed value and the next deviates by more than 3 times the standard deviation of this difference for the entire period, the observation was removed.

For the production data, data were only used when no error code from the site was given. Thus, the reduction in observed production should be caused by icing. The observed production loss was calculated from the ratio between the observed production and the potential production, given the observed wind speed and the ice-free power curves. A value of $30 \%$ means $30 \%$ less production than the potential production.

\subsection{Uncertainty quantification approaches}

Two methods for uncertainty quantification are employed in this study; ensemble forecasting and the neighbourhood method.

Ensemble forecasting is used here to account for uncertainties in the initial and boundary conditions within the NWP model HarmonEPS as described above. The possibility to include model errors in the ensemble prediction system was omitted in order to stay as close as possible to the operational set-up of the NWP model.

The neighbourhood method, following Mittermaier (2014), is used in order to capture the local uncertainty in the NWP data, e.g. the uncertainty in the representativeness of the forecast for a specific location of the wind turbines. Averaging forecasts made at several grid points around an observation site results in a better forecast than one single forecast from the kilometre-scale NWP. Furthermore, the spread of the forecast from the neighbouring grid points provides an estimate of the forecast uncertainty. Here, the 25 nearest grid points to an observation site are chosen as 
equally likely forecasts. Since these grid points are some kilometres apart from the turbine site, the height difference of the local topography can be several hundred metres. Two versions of the neighbourhood method were tested. In the first version, which is also the version presented in the Results section (Sect. 3.2.3), model data from the same height above sea level was used for all grid points, resulting occasionally in a height above ground much larger than the wind turbine height. The other version tested was a terrain-following method, where model data from the same height above ground was used for all grid points, meaning that $\Delta h$ in Eq. (1) is the same for all grid points. The different versions are further discussed in the Results section.

The control member (CM) from the ensemble forecast is used as baseline, as it reflects the use of a single deterministic forecast. In order to quantify the role of the different uncertainty sources in the forecast uncertainty, the benefit of using different combinations of the two above methods compared to baseline is investigated.

Four different combinations of the two methods were studied. These four uncertainty quantification approaches are in addition to CM presented in Fig. 3 and are described below.

- CMngb (control member neighbourhood): the model chain starts with a single NWP forecast, namely the CM from the ensemble forecast. Next, the neighbourhood method is added providing multiple forecast input to the icing and production model. This approach results in 25 forecasts from the 25 neighbouring grid points.

- EM (ensemble mean): the model chain starts with the ensemble forecast from HarmonEPS. The 11 ensemble members (the 10 perturbed members and the 1 control member) are then averaged before the icing forecast, providing the single statistically best meteorological input for the icing and production model. The uncertainty in the icing and production forecasts cannot be determined.

- ENS (ensemble): the first modelling step is based on the ensemble forecast. All ensemble members are then used each as input to the icing and production loss models, resulting in 11 forecasts of icing and production loss. The 11 forecasts give an estimation of the uncertainty in the icing and production forecasts.

- ENSngb (ensemble neighbourhood): the ensemble and the neighbourhood method combined. The neighbourhood method is added to each ensemble member after the NWP model step, resulting in 25 forecasts for each ensemble member and a total of 275 forecasts used as input to the icing and production model.

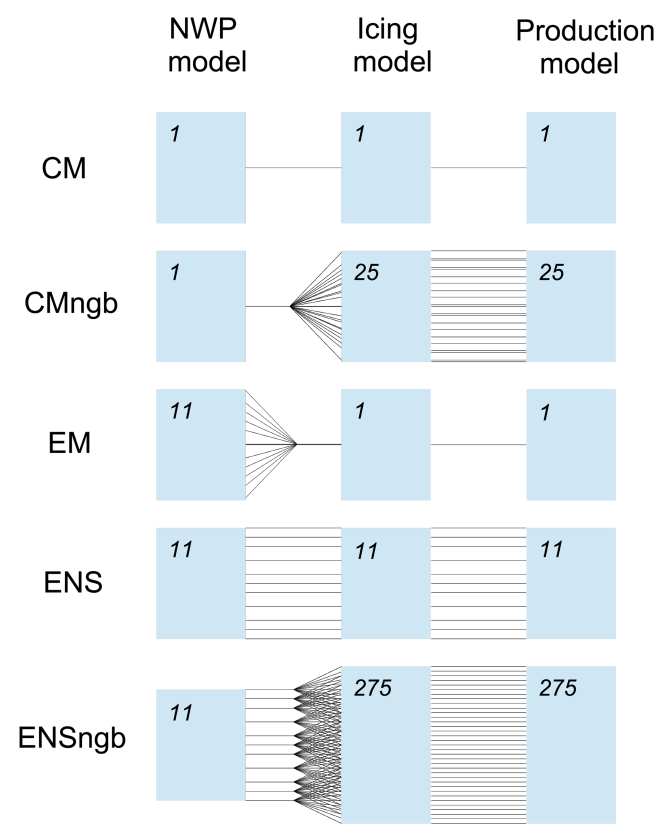

Figure 3. Uncertainty quantification approaches. The commonly used approach CM and the four uncertainty quantification approaches. CM: control member, a single forecast used in each forecast step. CMngb: control member together with the neighbourhood method. EM: ensemble mean, averaging the ensemble members after the first modelling step. ENS: ensemble, using all ensemble members throughout all modelling steps. ENSngb: ensemble together with the neighbourhood method. The number in each box represents the number of forecast members in each forecast step.

\subsection{Verification methods}

The forecast skill is assessed by the root mean squared error (RMSE), the mean forecast error called bias, and the unbiased forecast error, i.e. the standard deviation (SD) of the forecast error. They are connected by

$\mathrm{RMSE}^{2}=$ bias $^{2}+\mathrm{SD}^{2}$.

The calculation of the forecast error as the deviation between forecasted and true value uses an observation as replacement for the truth. Thus, the observational error needs to be taken into account in the calculation of the error terms. Due to the lack of a consistent estimate for the observational error, the observational error is neglected. This leads to an overestimation of the RMSE, bias and SD.

The magnitude of the bias of the meteorological parameters in this study varied between the observation sites and with forecast lengths. Thus, the average bias for each forecast length was estimated and removed from the RMSE to get SD.

By averaging the ensemble members for the same valid time, they can be treated in the same way as a single forecast, and the same skill scores can be used allowing us to com- 
pare the skill of the different probabilistic approaches with the skill of the single deterministic forecast denoted as $\mathrm{CM}$.

The spread of the ensemble forecast contains important additional information compared to a deterministic forecast, such as a situation-dependent estimate of the forecast uncertainty. The spread, SPRE, is defined as

$$
\mathrm{SPRE}=\sqrt{\frac{1}{M-1} \sum_{i=1}^{M}\left(x_{i}-\bar{x}\right)^{2},}
$$

where $x_{i}$ is the $i$ th forecast member, $\bar{x}$ is the ensemble mean and $M$ is the number of forecast members.

In a perfect probabilistic forecast, any of the simultaneous forecast members would be statistically indistinguishable from the truth. If this is not the case, the forecast uncertainty is over- or underestimated, i.e. providing a too wide or a too narrow range of forecast outcomes, respectively. In order to verify the ensemble spread (SPRE), it is compared to the forecast skill of the ensemble mean in terms of unbiased forecast error (SD) following Johansson (2018).

Both the SD and the SPRE are statistically expected to increase with increasing forecast length. In a perfectly calibrated forecast, the spread should be as large as the skill. The so-called spread-skill relationship of the forecasts, SPRE$\mathrm{SD}$, should therefore equal 1 . As the unbiased forecast error $\mathrm{SD}$ is overestimated due to the neglected observational error as mentioned above, the spread-skill relationship will consequentially be underestimated. This error could be corrected with an appropriate estimate of the observational error (Schwartz et al., 2014).

The skill of the forecasts made with the different approaches from Sect. 2.3 and the spread-skill relationship are presented below. Since a relatively short period of forecasts is studied with only two icing events, it is not possible to test the significance of the statistical measures. The results should therefore only be considered to show the potential benefit of the use of probabilistic forecasting for wind power in cold climates.

\section{Results}

\subsection{Meteorological parameters}

For the 2-week period examined in this study, the skill of the basic meteorological model performance is presented in Fig. 4 in terms of bias and unbiased forecast error for relative humidity, wind speed and temperature for the $42 \mathrm{~h}$ forecasts. The statistics are based on all forecasts at all 10 observation sites for each forecast length. The unbiased forecast error averaged over the forecast window amounts to about $7 \%, 2.3 \mathrm{~m} \mathrm{~s}^{-1}$ and $0.9^{\circ} \mathrm{C}$ for relative humidity, wind speed and temperature, respectively. The forecast error is expected to increase with forecast length, which is the case for temperature (Fig. 4c). The unbiased forecast error of the wind speed and relative humidity (Fig. 4a and b), however, displays a flat
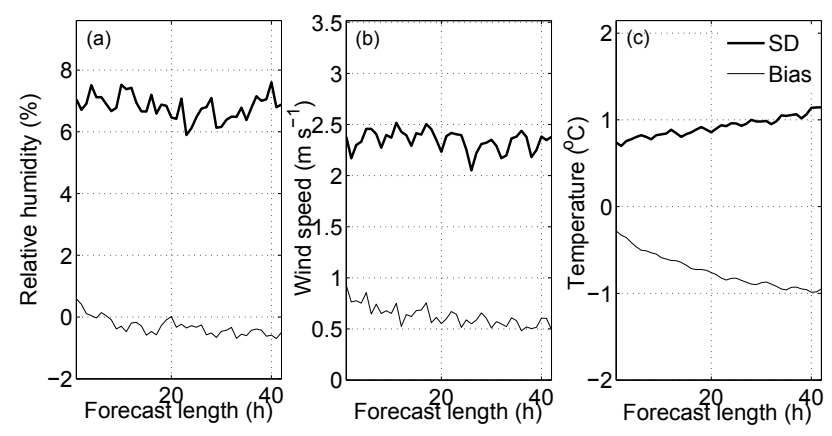

Figure 4. CM: unbiased forecast error SD and bias for (a) relative humidity in percent, (b) wind speed in $\mathrm{m} \mathrm{s}^{-1}$ and (c) temperature in ${ }^{\circ} \mathrm{C}$ for increasing forecast length. The statistical measures are calculated for the 2 -week period and averaged over all available stations. The meteorological observations at 60 to $150 \mathrm{~m}$ height above ground from 10 sites ( 9 for wind speed) are used.

shape suggesting that the error is saturated during the forecast window. This behaviour points to a difficulty in the analysis, i.e. the initialization of the wind field in the model. One aspect in this regard is the lack of wind observations in the planetary boundary layer to initialize the meso-scale wind field.

The temperature bias increases from $-0.3^{\circ} \mathrm{C}$ to close to $-1^{\circ} \mathrm{C}$ after $42 \mathrm{~h}$ (Fig. $4 \mathrm{c}$ ). This behaviour might be caused by a spin-up problem in the model, since it is changing with forecast length. Additionally, a negative temperature bias that is not changing with forecast length can be attributed to the warm turbine affecting the measurements. A difference in the temperature bias between mast (Mast) and turbine (WT) measurements amounts on average to $-0.4^{\circ} \mathrm{C}$ for mast and $-1.1^{\circ} \mathrm{C}$ for turbine. The bias of the wind speed (Fig. $4 \mathrm{~b}$ ) decreases slightly with forecast length from 1 to $0.5 \mathrm{~m} \mathrm{~s}^{-1}$ after $42 \mathrm{~h}$. The bias in the relative humidity (Fig. 4a) displays only small changes with forecast length and remains generally small with absolute values less than $1 \%$.

In general, the meteorological model displays good performance for the basic meteorological parameters. The lack of forecast error growth in wind speed and relative humidity suggests that the model forecast could be improved by assimilating more observations, especially for wind and humidity. A better initial state of the forecast might even improve the bias behaviour.

The meteorological performance of the different uncertainty quantification approaches in terms of spread and skill is shown in Fig. 5. The skill as defined as the unbiased forecast error $\mathrm{SD}$, and spread for the temperature forecasts is displayed for each approach. The baseline approach of a deterministic forecast (CM) shows the largest forecast error. For the examined period, the benefit of using the neighbourhood and/or ensemble methods can already be seen in the first hours of the forecasts, and increases with forecast length as expected. The CMngb has the smallest improve- 


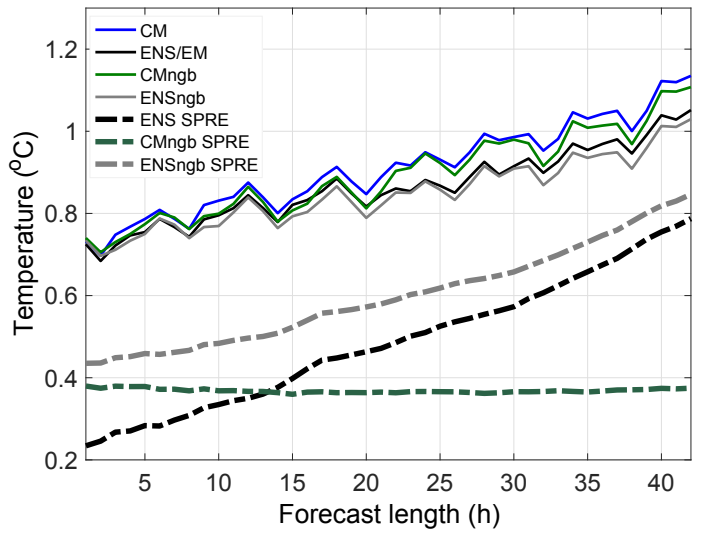

Figure 5. Unbiased forecast error SD for all uncertainty quantification approaches for the temperature in ${ }^{\circ} \mathrm{C}$ and the spread, SPRE, for the three approaches consisting of multiple forecasts as a function of increasing forecast length. The SD is calculated for the average forecast in case of multiple forecasts, i.e. approaches CMngb, ENS and ENSngb.

ment of forecast error, but still suggesting that the neighbourhood method is valuable if an ensemble forecast is not available. Even higher improvement is achieved by the approaches ENS and EM that provide by construction the same values here. The largest reduction of the forecast error is achieved using both the ensemble forecast method and the neighbourhood method (ENSngb), with an average reduction of $9 \%$ for the temperature, $7 \%$ for the wind speed and $12 \%$ for the relative humidity forecast error, averaged for all sites and all forecasts averaged for all sites and all forecasts.

Figure 5 also displays the forecast spread of the approaches ENS, ENSngb and CMngb. The spread is always clearly lower than the unbiased forecast error, which means that the forecast uncertainty is underestimated in all approaches. This behaviour might result from neglected uncertainty sources in the modelling chain (Fig. 1) The employed ensemble represents uncertainties in the initial and boundary conditions, but it does not take into account uncertainties in the model physics or numerical formulations. There are methods to account for these uncertainties, such as stochastic physics, which increase the spread (Bouttier et al., 2015), but they are not in the scope of this study. It is also important to consider the observational error when validating the spreadskill relationship of the forecast, as discussed in Sect. 2.4. Since the forecast error estimate is not corrected for the observational error, the under-dispersiveness of the approaches is not as large as it appears in Fig. 5.

On its own, the ensemble forecasting method (ENS) has better skill, spread and spread-skill relationship than the neighbourhood method (CMngb) for this period, around 0.6 and 0.3 , respectively, for all meteorological parameters. Specifically, the spread-skill relationship improves from around 0.3 for CMngb to around 0.6 for ENS for temper-
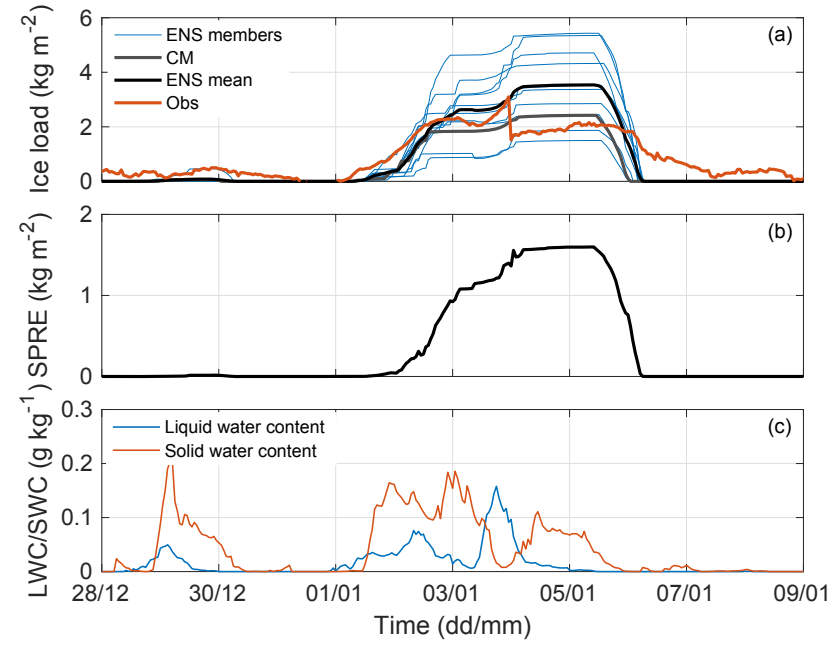

Figure 6. Site A. (a) Forecasted ice load in $\mathrm{kg} \mathrm{m}^{-2}$. Blue lines are ensemble members, grey line is the CM and black line is the ENS mean. The ice load observations are in red. (b) The related spread of the ensemble members in ENS. (c) Forecasted ENS ensemble mean liquid water content in $\mathrm{g} \mathrm{kg}^{-1}$ for the period.

ature, wind speed and relative humidity. The approach ENSngb results in the best spread-skill relationship around 0.7. This implies that the neighbourhood method is adding additional information about the forecast uncertainty, which is valuable for both the forecast skill and the forecast spread. The spread resulting from the neighbourhood method is constant with forecast length (CMngb in Fig. 5), since it represents the internal variations in the weather over the scale of the neighbourhood domain, but it does not take into account uncertainties due to initial boundary conditions, or model formulations that increase with increasing forecast length.

\subsection{Forecasted icing and production losses}

The forecasted icing is, as mentioned before, more difficult to validate since the observations of icing are unreliable. Alternatively, the forecasted production loss for the three sites with production data is also considered as a measure of the forecast skill of the icing. Results from two of the three sites, here $\mathrm{A}$ and $\mathrm{B}$, with consistent production observations will be presented in more detail in the following to point out some interesting features when using the probabilistic forecasts. Site $\mathrm{C}$ is not shown, but had icing during about 3 days of the 2 weeks. In Sect. 3.2.3, the average skill and spread of the different approaches for the three sites are discussed. Sites A and $\mathrm{C}$ were affected by a frontal passage during the 2 weeks, while site A experienced general cloudiness and was less influenced by this front. 

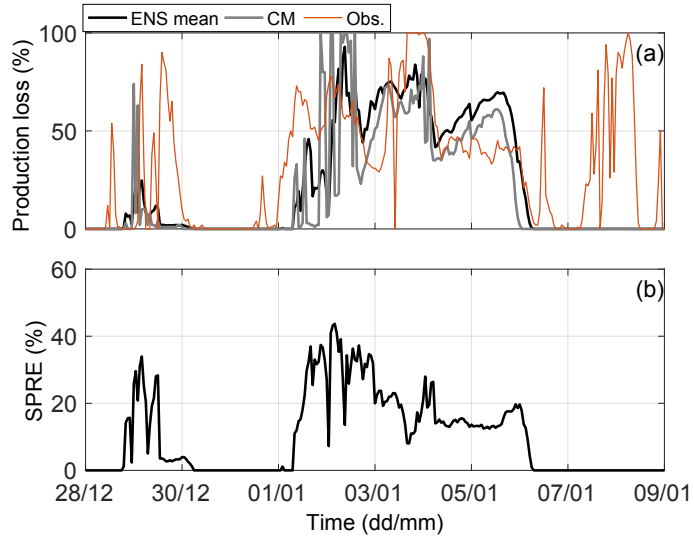

Figure 7. Site A. (a) Forecasted production loss in percent. Black line is the ensemble mean using ENS, grey line is the CM and red line is the observed production loss. (b) The related spread of the ensemble members in ENS.

\subsubsection{Site A}

Two icing events were forecasted at site A during the 2 weeks. During the first icing event, around the 30 December, only a small amount of ice is forecasted, while during the second icing event, starting around 1 January, both the modelled and observed ice load amounted to several $\mathrm{kg} \mathrm{m}^{-2}$. In Fig. 6a the forecasted icing using the ENS approach and the $\mathrm{CM}$ approach is presented together with the ensemble mean of the ENS approach and observed ice load. The spread of the ensemble members from the ENS, which displays the forecast uncertainty in the icing, are presented in Fig. 6b. During the icing events, the spread signals uncertainty in the ice amount. The largest forecast uncertainty is found at the end of the second icing event with around $1.5 \mathrm{~kg} \mathrm{~m}^{-2}$. The magnitude of the overall forecast uncertainty, or spread, amounts to about $50 \%$ of the ice load here.

In this period, first the build up and then the loss of ice happen almost simultaneously for all the ensemble members. This is especially visible in the spread for the second icing event with values close to zero at the start and end of the event. Forecasted and observed production loss for the site allow for studying the timing during the event in more detail (Fig. 7a). The forecasted production loss starts about $12 \mathrm{~h}$ later than the observed production loss, pointing to a problem with the agreement between the ensemble members. A closer examination reveals low forecasted liquid and solid water contents in the beginning of the icing period (Fig. 6c), resulting in no accumulation of ice by the icing model. Instead the ice starts to accumulate in the model when solid water components are forecasted, in addition to the liquid water content. Interestingly, all ensemble members behave very similarly with this timing (not shown). This could be related to an error in the modelled cloud characteristics or in the icing model causing a too slow ice buildup.
Additionally, the ensemble fails to describe the end of the icing period (6-9 January) where the modelled production loss drops to zero for the remaining period, while the observed production loss is high around 8 January (Fig. 7a). The end of the 2 weeks also lacks forecasted liquid and solid water contents, and thus no further buildup by the icing model is possible. Again, the ensemble was overconfident with all members displaying a similar behaviour. By including the neighbourhood method to the ensemble, there is some improvement in the end of the 2 weeks adding some forecasted liquid water content at the end of the simulation (Fig. 8) in some members. However, the amount of forecasted water content was still too low to generate any notable buildup by the icing model.

A closer look at the weather situation shows that site A is affected by a frontal passage during the second week. The ensemble members all have the front passage at the same time, resulting in similar values for cloud cover as well as liquid and solid water contents. This problem results from the insufficient representation of the uncertainties in the boundaries. The boundary data from different members of the ECMWF EPS prescribes very similar surface pressure patterns for this event resulting in an overconfidence in the arrival time of the cloud front. Furthermore, small scales are initialized for all ensemble members in the same way using the control member analysis. During the icing event, however, the ensemble members have a spread of around $25 \%$ of the ENS mean value for liquid and solid water components, leading to a spread in the amount of built-up ice (Fig. 6c). In Davis et al. (2014) it was shown using a similar model that the resulting ice load was highly sensitive to a variation in the ingoing median volume droplet size of the water droplets, suggesting that this is an uncertain part of the icing model. Here, the droplet size is calculated from the liquid/solid water content before being used in the icing model. This is discussed further in the section below (Sect. 3.2.2).

\subsubsection{Site B}

At site B only one icing event was forecasted and observed, starting already on the first days of the period. This site was not as strongly affected by frontal passages as site A, and had more general cloudiness during the period. Figure $9 \mathrm{a}-\mathrm{c}$ shows the forecasted and observed ice load, spread of forecasted ice load and liquid water content. In Fig. 10a-b the forecasted and observed production loss as well as the related forecast spread is presented.

In the beginning of the 2 weeks, there is 1 day with a large amount of liquid and solid water content; however, no ice started to build up during this day, mainly because of too low wind speeds. At the start of the actual icing event, the ice growth is first small, but with increasing pace after 1 January 2012 , reaching the largest load of about $2.5 \mathrm{~kg} \mathrm{~m}^{-2}$ on 4 January (Fig. 9a). The observed production loss shows a similar behaviour (Fig. 10). In Fig. 11a the ENS mean me- 


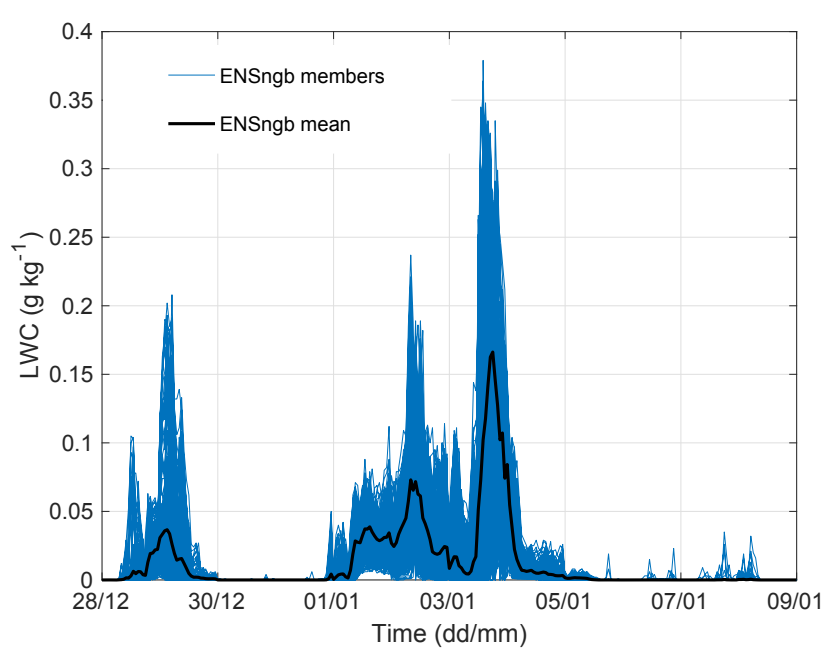

Figure 8. Site A. Forecasted liquid water content in $\mathrm{g} \mathrm{kg}^{-1}$ using the ENSngb approach.

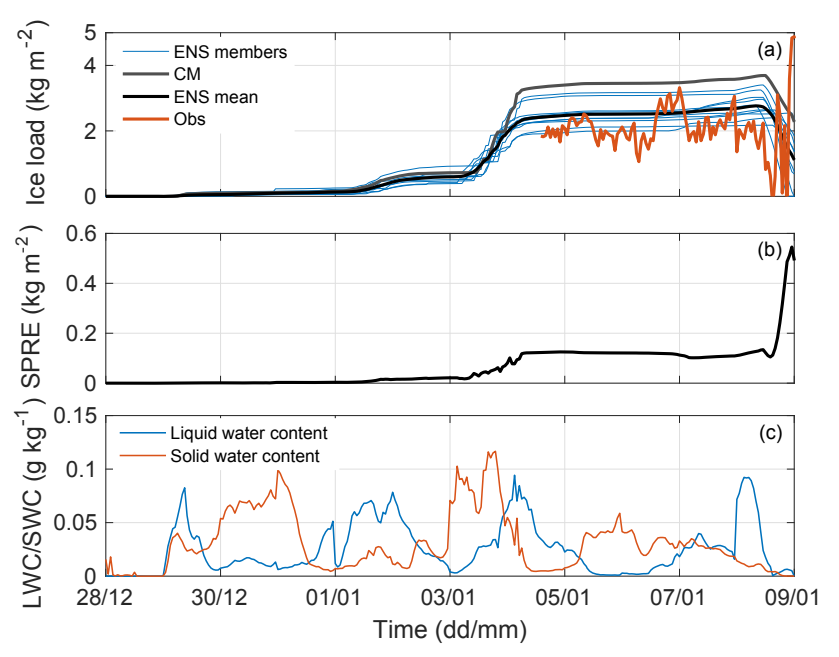

Figure 9. Same as Fig. 6, but for Site B.

dian volume diameter (MVD) for the solid water components can be seen for this site and the corresponding mean spread is shown in Fig. 11b. The liquid water components ENS mean MVD is not shown, as it follows the liquid water content amount in this case (Fig. 9c). Large values of MVD (Fig. 11a) coincide with large icing rates (Fig. 9a) stressing the role of MVD for the icing intensity. The large spread of the MVD around 4 January (Fig. 11b) can be connected to the ice load differences of the different ensemble members (Fig. 9a) and also to the simultaneous spread in the production loss forecast (Fig. 10b). This behaviour agrees with the effect of different MVDs discussed in Davis et al. (2014).

Generally, the forecasted ice and production loss displays a reasonable agreement with observations. However, there are two interesting deviations. Firstly, in the first half of the time series the forecast is generally underestimating the ob-

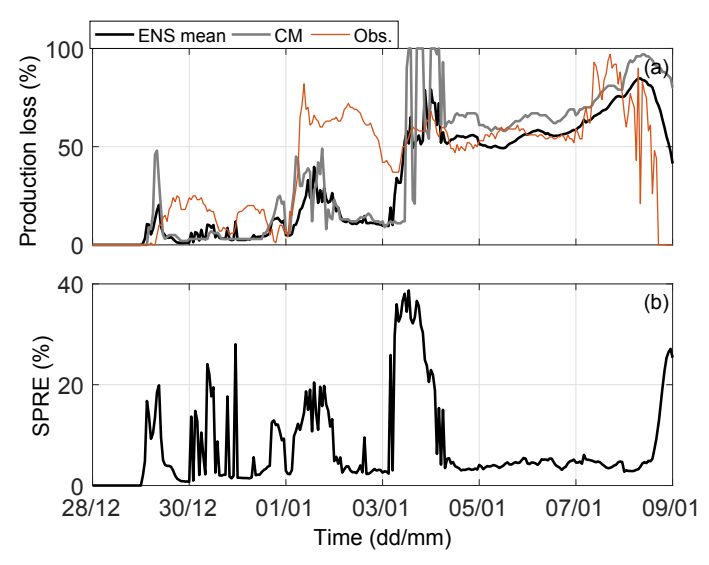

Figure 10. Same as Fig. 7, but for Site B.

served production loss (Fig. 10), while the forecasted ice load agrees well with the observations (Fig. 9a). The reason of the disagreement seems to be related to deficiencies in our production model. Secondly, the observed drop in both ice load and production loss at the end of the period is delayed in all forecasts, opposite to the behaviour at site A.

The high forecast spread, or forecasted uncertainty in the icing forecast (Fig. 9b), shows the value of having a probabilistic forecast. This variation of the ensemble members is probably due to a large variation in the liquid and solid water contents (between $25 \%$ and $50 \%$ of the mean amount) resulting in a variation of the calculated MVD. The benefit of an ensemble in this case can also be seen in Fig. 10a where the ensemble mean (black line) of the production loss forecast starts to decrease, getting closer to observations, while the $\mathrm{CM}$ is remaining nearly at $100 \%$. The forecast spread of the production loss is also increasing during the last day of the period, suggesting an enlarged uncertainty in the forecast. Generally, forecasting the end of an icing period has been shown to be challenging due to the difficulties in modelling ice loss (e.g. Davis, 2014). On the other hand the start of the stronger icing period from the 3 January is well timed in the forecast data; and furthermore, the spread of the production loss forecast increases from approximately $5 \%$ to $30 \%$ simultaneously. This increased spread is a useful indicator for the uncertainty in the start of the ice period and provides additional information to the actual forecast.

\subsubsection{Forecast performance of the different approaches}

In Fig. 12a the forecasted next-day production using the four different uncertainty quantification approaches are compared with the single forecast of $\mathrm{CM}$ and observed production for site A. For the approaches that generate multiple forecasts, the average of the forecast members is presented.

The different approaches are following the observed production most of the time. As the figure suggests visually, and the RMSE calculation below confirms, the ENSngb mean is 

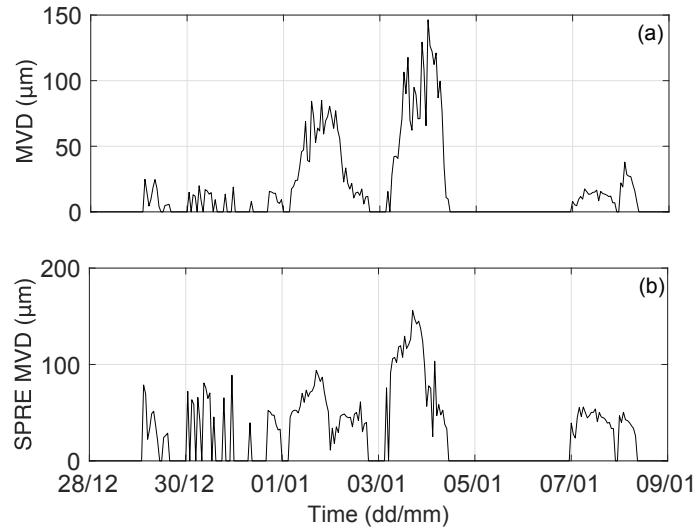

Figure 11. Site B. (a) ENS mean MVD for the solid water components. (b) Mean spread of MVD for the solid water components.

the most skillful approach for this site. A closer inspection of Fig. 12a reveals some typical behaviour for the approaches. All approaches overestimate the production during the start of the second icing period around 1 January, which agrees with the underestimated production loss in Fig. 10a. The different model forecasts tend to overestimate the production occasionally. This probably happens due to an overestimation of the potential production, since the wind speed has a positive bias (Fig. 4b). A bias correction of the wind speed would be useful to reduce this error.

In Fig. 12a the single forecast of CM has stronger variations than the other approaches. These variations are partly a sign of uncertainty in the forecast and belong to unpredictable phenomena. They are filtered out when averaging over the members of the probabilistic approaches. However, it is important to realize that this filtering creates a so-called unoccupied average, i.e. the smoothed state is unrealistic, since part of the variance is now included in the spread of the forecast members describing the forecast uncertainty. This spread for the uncertainty quantification approaches can be seen in Fig. 12b. The ensemble (ENS) provides a larger spread than the neighbourhood method applied to a single forecast (CMngb). Similar to the meteorological parameters, the largest spread, and thus forecasted uncertainty, is generally seen for the combination of ensemble and neighbourhood method (ENSngb). The average spread to skill ratio of the ENSngb production forecast amounts to around 0.7, compared to 0.5 for ENS. The increased spread for the ENSngb should therefore provide the best estimate for the actual forecast uncertainty, even if the model is still overconfident.

As a summary of the forecast performance, Table 2 yields the mean error as RMSE of the 06:00 UTC $+18-42 \mathrm{~h}$ forecasts for the production loss and for the production, averaged over the three observation sites where production data were available. The forecast quality of the production forecast using the different approaches generally follows the order in the first step of the modelling chain, i.e. for the meteorolog-
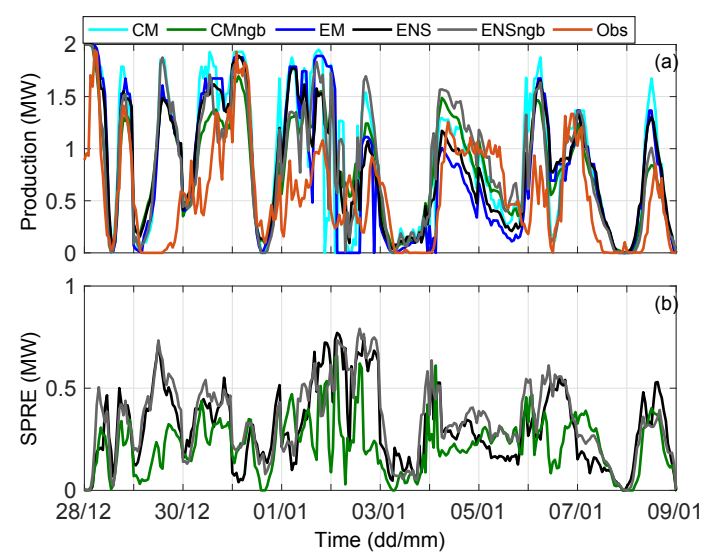

Figure 12. (a) Production forecast in MW at site A for the different approaches (Fig. 3). For CMngb, ENSngb and ENS the lines present the average of the multiple forecasts. Observed production is given with the dash-dotted line. The production is calculated for a $2 \mathrm{MW}$ turbine. (b) The spread of the multiple members in CMngb, ENSngb and ENS.

ical parameters (Fig. 3). The benefit of the neighbourhood method for the production loss forecast can be seen comparing the RMSE for CM and the CMngb. However, the production loss RMSE is the same for ENS and ENSngb, suggesting that the neighbourhood method neither contributes to nor reduces the forecast skill when added to the ENS approach. Using the ENS or ENSngb approach compared to CM results in a reduction of the production loss forecast error from $26 \%$ to $21 \%$. It should be noted that the usage of the ensemble mean as the input to the icing and production loss model (approach EM) deteriorates the forecast quality to $29 \%$ compared to the ensemble-based approach ENS with $21 \%$, where the output from each member is calculated through the entire chain. This results from the non-linearity of the icing and production loss model. The increased forecast quality for the forecasted meteorological parameters by the ensemble mean is lost by the usage of the unoccupied average as input into the icing and production model.

For the production forecast, the best forecast is provided by the ENSngb approach, while the worst comes from the single forecast of CM. Here, adding the neighbourhood method to the ENS approach reduces the RMSE (Table 2). Using the ENSngb approach compared to CM results in a reduction of the production forecast error from 0.49 to $0.41 \mathrm{MW}$ or by $16 \%$ relative to the CM forecast.

The two different versions of neighbourhood methods, i.e. terrain-following or constant-height version described in Sect. 2.1.1, displays some differences for the production forecast. Assuming that wind power is installed at higher elevation than the surroundings, the terrain-following version provides neighbours from lower absolute heights with higher moisture content, and thus more atmospheric icing, and more surface-affected wind fields compared to the constant-height 
Table 2. RMSE of the different approaches for production and for production loss forecasts averaged over the three sites with production data. The production is calculated for a $2 \mathrm{MW}$ turbine.

\begin{tabular}{lrr}
\hline Approach & Production (MW) & Production loss (\%) \\
\hline CM & 0.49 & 26 \\
CMngb & 0.44 & 23 \\
EM & 0.47 & 29 \\
ENS & 0.44 & 21 \\
ENSngb & 0.41 & 21 \\
\hline
\end{tabular}

version. The quality of the resulting production loss forecast is very similar for the two versions, resulting in the same RMSE. For the final production forecast, however, an improvement is seen from the constant-height version compared to the terrain-following one which can be traced back to better wind forecasts from the constant-height neighbourhood method.

It should be pointed out once more that the statistical significance of the results could not be assessed since this is a case study with a limited sample size, but the results are consistent in the different analyses and supports theoretical expectations. The improved forecast skill of the production loss and of the production, using the four probabilistic forecasting approaches instead of the single forecast of $\mathrm{CM}$, also suggests that the icing forecast is improved, even though it is not possible to validate with the available ice load observations.

\section{Concluding remarks}

The problem of predicting next-day production losses due to icing of wind turbines has been addressed with the usage of probabilistic forecasting. Two methods, ensemble forecasting and the neighbourhood method, have been used in four different uncertainty quantification approaches to produce probabilistic forecasts. Improved skill and estimations of the forecast uncertainty were both investigated in this 2week case study. The main results are the following:

- Using probabilistic forecasting improves the forecast skill for the meteorological parameters, the icing and the icing-related production loss compared to the commonly used approach with one single deterministic forecast.

- The spread of the multiple forecasts can be used as an estimation of the forecast uncertainty, also for icing and related production losses. However, with the current model set-up, the uncertainty is underestimated both for the meteorological parameters and for the production.

- The approach where both the uncertainties in initial and boundary conditions and the representativeness of the wind turbine are represented, ENSngb, has the highest skill for the next-day production forecast. This suggests that both errors should be taken into account when generating a probabilistic forecast.

Improving the skill by the use of an ensemble forecast is a useful contribution to wind power forecasting in cold climate. Additionally, a reliably forecasted uncertainty can be of great value for end-users as probabilistic forecasts of icing events and related production losses. Even though the spread of the forecast is too low and, hence, the forecast uncertainty underestimated, it could be utilized if the spread was calibrated (e.g. see Veenhuis, 2012, or Sloughter et al., 2012). Knowing the likelihood for icing, the end-user can employ site-specific cost-loss ratios in the decision-making and trading processes, the use of de-icing systems, and for the safety of people working at the wind farm.

To further develop the use of probabilistic forecasting in this area, it is important to note that we are not taking into account all of the uncertainties in the modelling chain, e.g. errors resulting from approximations made in the different models. It is known that the icing model contains numerous uncertain parameters, such as the sticking efficiency in case of snow and wind erosion (Davis et al., 2014; Nygaard et al., 2013). The inclusion of these uncertainties into the entire modelling chain is currently ongoing research.

The weather is the most fundamental part of the modelling chain and due to its chaotic behaviour the focus here is the meteorological model. As the forecast skill for wind speed and relative humidity at nacelle height appeared to be saturated during the first 42 forecast hours, more effort is required in order to improve the initial state of the forecast, e.g. through data assimilation methods or inclusion of local observations of humidity and wind, by radar and other instruments. From the meteorological spread-skill relationship, it can be concluded that more spread is also needed. The lack of spread in the ensemble was especially visible during a frontal passage where all members had very similar boundary conditions and thus the same timing of the frontal passage. Better spread from the boundary conditions can be achieved by a smart selection of the global host model ensemble members (Molteni et al., 2001). Furthermore, full-scale data assimilation for all ensemble members, and not only for the control member, would allow for a better spread in the initial state of the ensemble members.

Finally, a NWP-ensemble forecast is computationally expensive to run and requires extensive infrastructure. Thus, generally, only national meteorological services can operationally produce ensemble forecasts. Many national weather services currently run an operational ensemble forecast that is often disseminated as open data following the European INSPIRE directive. The delivery time for such data are around $3 \mathrm{~h}$ after analysis time, thus making it possible to use the 06:00 UTC model run for next-day wind power forecasts. Many users will then be able to include this forecast data into their own icing and production models, which are far less 
computationally expensive. This will allow for a wide application of probabilistic weather forecasting for wind power in cold climates.

Data availability. The data used in figures and tables can be acquired by contacting the first author (jennie.molinder@geo.uu.se).

Author contributions. JM has the main responsibility for the simulations, analysing the data and preparing the manuscript. EO constructed the icing and production model and supported the setup of the modelling chain. HK and HB developed the initial idea in a research proposal. HK supported the structuring of the article and during the writing by JM. AS and HB reviewed the article in several stages. This work is part of JM's PhD under supervision of AS, HK and HB.

Competing interests. The authors declare that they have no conflict of interest.

Acknowledgements. The authors would like to thank the Swedish Energy Agency for financing the project within the programme "Wind Power in Cold Climate", project number 37279-1.

Edited by: Jakob Mann

Reviewed by: two anonymous referees

\section{References}

Al-Yahyai, S., Charabi, Y., Al-Badi, A., and Gastli, A.: Nested ensemble NWP approach for wind energy assessment, Renew. Energ., 37, 150-160, https://doi.org/10.1016/j.renene.2011.06.014, 2011.

Andrae, U. and MetCoOp-Team: ALADIN-HIRLAM Newsletter, available at: http://www.umr-cnrm.fr/aladin/meshtml/NL8-final. pdf (last access: 1 October 2018), 2017.

Bengtsson, L., Andrae, U., Aspelien, T., Batrak, Y., Calvo, J., De Rooy, W., Gleeson, E., Hansen-Sass, B., Homleid, M., Hartal, M., Ivarsson, K.-I., Lenderink, G., Miemelä, S., Pagh Nielsen, K., Onvlee, J., Rontu, L., Samuelsson, P., Santos Munoz, D., Subias, A., Tijm, S., Toll, V., Yang, X., and Ødegaard Køltzow, M.: The HARMONIE - AROME Model Configuration in the ALADIN - HIRLAM NWP System, Mon. Weather Rev., 145, 1919-1935, https://doi.org/10.1175/MWR-D-16-0417.1, 2017.

Bergström, H., Olsson, E., Söderberg, S., Thorsson, P., and Undén, P.: Wind power in cold climates, Ice mapping methods, Tech. rep., Elforsk, Stockholm, available at: http://www.diva-portal. org/smash/record.jsf?pid=diva2:704372\&dswid=6571 (last access: 1 October 2018), 2013.

Bouttier, F., Raynaud, L., Nuisser, O., and Ménétrier, B.: Sensitivity of the AROME ensemble to initial and surface perturbations during HyMeX, Q. J. Roy. Meteor. Soc., 142, 390-403, https://doi.org/10.1002/qj.2622, 2015.

Bowler, N. E., Arribas, A., Mylne, K. R., Robertson, K. B., and Beare, S. E.: The MOGREPS short-range ensemble pre- diction system, Q. J. Roy. Meteor. Soc., 722, 703-722, https://doi.org/10.1002/qj.234, 2008.

Combitech AB: The Ice load surveillance sensor Icemonitor, Tech. rep., available at: http://www.rwis.net/res/pdffiles/IceMonitor_ Product_Sheet.pdf (last access: 1 October 2018), 2016.

Davis, N., Hahmann, A. N., Clausen, N. E., and Žagar, M.: Forecast of icing events at a wind farm in Sweden, J. Appl. Meteorol. Clim., 53, 262-281, https://doi.org/10.1175/JAMC-D-1309.1, 2014.

Davis, N. N.: Icing Impacts on Wind Energy Production, PhD thesis, DTU Wind Energy, available at: http://orbit.dtu.dk/files/104279722/Icing_Impacts_on_Wind_ Energy_Production_final.pdf (last access: 1 October 2018), 2014.

Davis, N. N., Pinson, P., Hahmann, A. N., Clausen, N.-E., and Žagar, M.: Identifying and characterizing the impact of turbine icing on wind farm power generation, Wind Energy, 16, 15031518, https://doi.org/10.1002/we.1933, 2016.

Du, J., Mullen, S. L., and Sanders, F.: Short-Range Ensemble Forecasting of Quantitative Precipitation, Mon. Weather Rev., 125, 2427-2459, https://doi.org/10.1175/15200493(1997)125<2427:SREFOQ>2.0.CO;2, 1997.

Du, J., MiMego, G., Tracton, S., and Zhou, B.: NCEP Short-range ensemble forecasting (SREF) system: Mulit-IC, multi-model and multi-physics approach, Tech. rep., Enviromental Modeling Centre/NCEP/NOAA, Washinton DC, USA, 2003.

ISO 12494: Atmospheric icing of structures (ISO/TC 98/SC3), Tech. rep., International Organization for Standardization, Geneva, Switzerland, 2001.

Johansson, Å.: Another look at Spread and Skill, in preparation, 2018.

Kraj, A. G. and Bibeau, E. L.: Phases of icing on wind turbine blades characterized by ice accumulation, Renew. Energ., 35, 966-972, https://doi.org/10.1016/j.renene.2009.09.013, 2010.

Leith, C. E.: Theoretical Skill of Monte Carlo Forecasts, Mon. Weather Rev., 102, 409-418, 1974.

Leutbecher, M. and Palmer, T. N.: Ensemble forecasting, J. Comput. Phys., 227, 3515-3539, https://doi.org/10.1016/j.jcp.2007.02.014, 2008.

Makkonen, L.: Models for the growth of rime, glaze icicles and wet snow on structures, Philos. T. R. Soc. Lond., 358, 2913-2039, https://doi.org/10.1098/rsta.2000.0690, 2000.

Mazin, I. P., Korolev, A. V., Heymsfield, A., Isaac, G. A., and Cober, S. G.: Thermodynamics of icing cylinder for measurements of liquid water content in supercooled clouds, J. Atmos. Ocean. Tech., 18, 543-558, https://doi.org/10.1175/15200426(2001)018<0543:TOICFM>2.0.CO;2, 2001.

Megner, L., Tan, D. G. H., Körnich, H., Isaksen, L., Hor, A., Stoffelen, A., and Marseille, G.: Linearity aspects of the ensemble of data assimilations technique, Q. J. Roy. Meteor. Soc., 141, 426432, https://doi.org/10.1002/qj.2362, 2015.

Mittermaier, M. P.: A Strategy for Verifying Near-ConvectionResolving Model Forecasts at Observing Sites, Weather Forecast., 29, 185-204, https://doi.org/10.1175/WAF-D-12-00075.1, 2014.

Molteni, F., Buizza, R., Marsigli, C., Montani, A., Nerozzi, F., and Paccagnella, T.: A strategy for high-resolution ensemble prediction. I: Definition of representative members and global-model experiments, Q. J. Roy. Meteor. Soc., 127, 2069-2094, 2001. 
Müller, M., Homleid, M., Ivarsson, K.-I., Køltzow, M., Lindskog, M., Midtb $\varnothing$, K. H., Andrae, U., Aspelien, T., Berggren, L., Bjørge, D., Dahlgren, P., Kristiansen, J., Randriamampianina, R., and Ridal, M.: AROME-MetCoOp: A Nordic Convective-Scale Operational Weather Prediction Model, Weather Forecast., 32, 609-627, https://doi.org/10.1175/WAF-D-16-0099.1, 2017.

Nygaard, B. E. K., Àgústsson, H., and Somfalvi-Tóth, K.: Modeling Wet Snow Accretion on Power Lines : Improvements to Previous Methods Using 50 Years of Observations, J. Appl. Meteorol. Clim., 52, 2189-2203, https://doi.org/10.1175/JAMC-D12-0332.1, 2013.

Pinson, P. and Kariniotakis, G. N.: Conditional Prediction Intervals of Wind Power Generation, IEEE Tranactions on Power Systems, 25, 1845-1856, https://doi.org/10.1109/TPWRS.2010.2045774, 2010.

Ronsten, G., Wallenius, T., Hulkkonen, M., Baring-Gould, I., Cattin, R., Durstewitz, M., Krenn, A., Laakso, T., Lacroix, A., Tallhaug, L., Byrkjedal, Ø., and Peltola, E.: IEA Wind Task 19, State-of-the-Art of Wind Energy in Cold Climates, Tech. rep., iea wind, available at: https://community.ieawind.org/HigherLogic/ System/DownloadDocumentFile.ashx?DocumentFileKey= 4c5e2354-f948-4441-5558-23e921c47627\&forceDialog=0 (last access: 1 October 2018), 2012.

Schäfer, M.: Entwicklung eines Windrampendetektors zur Unterstützung der Netzintegration von Windenergie, Mäster theses, Johannes Gutenberg Universität Mainz, Germany, 2014.

Schwartz, C. S., Romine, G. S., Smith, K. R., and Weisman, M. L.: Characterizing and Optimizing Precipitation Forecasts from a Convective-Premitting Ensemble Initialized by a Mesoscale Ensemble Kalman Filter, Weather Forecast., 29, 1295-1318, https://doi.org/10.1175/WAF-D-13-00145.1, 2014.

Seity, Y., Brousseau, P., Malardel, S., Hello, G., Bénard, P., Bouttier, F., Lac, C., and Masson, V.: The AROME-France ConvectiveScale Operational Model, Mon. Weather Rev., 139, 976-991, https://doi.org/10.1175/2010MWR3425.1, 2011.
Sloughter, J. M., Gneiting, T., and Raftery, A. E.: Probabilistic Wind Vector Forecasting Using Ensembles and Bayesian Model Averaging, Mon. Weather Rev., 141, 2107-2119, https://doi.org/10.1175/MWR-D-12-00002.1, 2012.

Thompson, G., Field, P. R., Rasmussen, R. M., and Hall, W. D.: Explicit Forecasts of Winter Precipitation Using an Improved Bulk Microphysics Scheme. Part II: Implementation of a New Snow Parameterization, Mon. Weather Rev., 136, 5095-5115, https://doi.org/10.1175/2008MWR2387.1, 2008.

Thorsson, P., Söderberg, S., and Bergström, H.: Modelling atmospheric icing: A comparison between icing calculated with measured meteorological data and NWP data, Cold Reg. Sci. Tech., 119, 124-131, https://doi.org/10.1016/j.coldregions.2015.07.003, 2015.

Traiteur, J., Callicutt, D. J., Smith, M., and Baiday Roy, S.: A Short-Term Ensemble Wind Speed Forecasting System for Wind Power Applications, J. Appl. Meteorol. Clim., 51, 1763-1774, https://doi.org/10.1175/JAMC-D-11-0122.1, 2013.

Veenhuis, B. A.: Spread Calibration of Ensemble MOS Forecasts, Mon. Weather Rev., 141, 2467-2482, https://doi.org/10.1175/MWR-D-12-00191.1, 2012.

Wallenius, T., Peltola, E., Lehtomäki, V., Antikainen, P., Bluemink, G.-J., Wadam-Gagnon, M., Dillingh, J., Clausen, N.-E., and Klintström, R.: World Market Update 2012, International Wind Energy Development, Tech. rep., Navigant Research, Chicago, Illinois, USA, 2013.

WMO: Guidelines on Ensemble Prediction Systems and Forecasting, Chair, Publication Board, Geneva, available at: http://www. wmo.int/pages/prog/www/Documents/1091_en.pdf (last access: 1 October 2018), 2012.

Yano, J.-I., Bengtsson, L., Geleyn, J.-F., and Brozkova, R.: Towards a Unified and Self-Consistent Parameterization Framework, in: Parameterization of Atmospheric Convection, edited by: Plant, R. S. and Yano, J.-I., Imperial collage press, London, 423-435, 2015. 